\title{
ON THE SHAPE OF THE MUSCLES OF THE TONGUE OF EUMECES LATISCUTATUS LATISCUTATUS
}

\author{
MICHIO MIYAZAKI ${ }^{1)}$ AND TAKAYUKI NAKAMURA ${ }^{2)}$ \\ The First Department of Anatomy Kurume University school of \\ Medicine. Kurume ${ }^{1}$, and The First Department of Oral Anatomy \\ Fukuoka Dental College, Fukuoka, 814, Japan ${ }^{2)}$
}

Received for publication October 5, 1980

\begin{abstract}
Due to the difference in the method of food catch and intake even in the same kind of animals the tongue and the muscles of the tongue are different in shape, respectively. Accordingly, morphological comparisons were performed between the muscles of the tongue of the amphibia, the reptiles, and the fish and those of Eumeces latiscutatus latiscutatus examined belonging to the reptiles.
\end{abstract}

\section{INTRODUCTION}

It is well known that the method of food catch and intake of every kind of animals depends upon the function of the muscles of the tongue. Thereupon, the muscles of the tongue of a newt, a bull frog, and a Xenopus loevis belonging to the amphibia, of a gecko belonging to the reptiles, and of a Bokophthalmus pectinirostris belonging to the fish have so far been investigated morphologically and comparative anatomically and their function considered. This time, on the shape of the muscles of the tongue of Eumeces latiscutatus latiscutatus belonging to the reptiles a report will be made.

\section{MATERIALS AND METHOD}

Materials used were Eumeces latiscutatus latiscutatus living throughout Japan except for a part of Hokkaido after fixation in a $10 \%$ formalin solution. The animals were beheaded from the neck. After decalcification, neutralization, washing, and dehydration as usual, the tissues were imbeded in paraffin, and serial sections of $10 \mu$ were prepared, double-stained with Hematoxylin-Eosin, and examined.

\section{FINDINGS}

The Os hyoideum of Eumeces latiscutatus latiscutatus lies on the ventral aspect of the mandibula. It consists of the basihyal bone which is cartilaginous and a part of whose tip intrudes into the tongue and of 2 pairs of the processes projecting from this before and behind: the cornu anterius and the cornu posterius.

On the other hand, regarding the muscle groups of the tongue participating in the tongue movement on the region of the tongue there are the $\mathrm{Mm}$. hyoidei laterales such as the M. genioglossus, M. geniohyoideus, M. hyoglossus and $\mathrm{M}$. sternohyoideus, and the $\mathrm{Mm}$. hyoidei mediales such as the M. trans- 
versus linguae, M. longitudinalis linguae, and $M$. verticalis linguae.

A detailed report of these muscle groups of the tongue is as follows:

1. M. genioglossus

The M. genioglossus, as seen in Figs. 3 and 4 , arises from the medial side of the tip of the mandibula, running back along the dorsal aspect of the M. geniohyoideus, and intrudes into the tongue from the body of the tongue to its root obliquely along the lateral side of the M. hyoglossus. However, this muscle which pulls the tongue out of the mouth functionally is poor in the development.

\section{M. geniohyoideus}

The M. geniohyoideus, as seen in Figs. 3, 4, 5, and 6, arises from the posterior surface of the fore end of the mandibula (sulcus mentalis), running back between the M. genioglossus and the M. inframandibulae, and passing through under the M. hyoglossus from the body of the tongue to its back, becomes a somewhat flattened muscle bundle and attaches to the lateral side of the tongue. This is also a muscle which pulls the tongue out of the mouth like the M. genioglossus.

\section{M. hyoglossus}

The M. hyoglossus, as given in Figs. 1-6, arises from the lateral side of the cornu posterius of the hyoid bone, running forward as a pair of the muscle bundle, right and left. After passing by the lateral side of the cartilagines laryngis, it penetrates the tongue at its origin. When it reaches the tip of the tongue, the bilateral muscle bundles gather in the median plane and present a shape embracing the body of the hyoid bone, which is a tubulous hyoid muscle surrounding this muscle. And then, as it moves from the hyoid body to its tip, the bilateral muscle bundles draw a little outward from the median plane and gradually dwindle away. Moreover, this is a muscle which pulls the tongue backward, and among the muscles penetrating the tongue it seems to be the most well-developed and function the most effectively.

\section{M. sternohyoideus}

The M. sternohyoideus, which is regarded as a continuation of the $M$. rectus abdominis, arises from the ventral side of the sternum, passing by the lateral side of the trachea, and attaches to the medial surface of the hyoid bone. This is also a muscle which pulls the hyoid bone backward.

\section{M. transversus linguae}

The M. transversus linguae, as seen in Figs. 1, 2, 3, 5, and 6, is observable below within the M. hyoglossus at the origin of the root of the tongue. It arises from the upper part of the medial side of this muscle, runs forward, and spreads toward the upper part of the lateral side. As it approaches the tip of the tongue, it gradually becomes one muscle band. Thus, it begins with the upper part of the M. hyoglossus (the lower part of the M. longitudinalis) and ends with the tip of the tongue.

\section{M. longitudinalis linguae}

The M. longitudinalis linguae, as seen in Figs. 1-5, is only observable in the back of the tongue and in the lower surface of the lateral side. The muscle bundle in the back of the tongue arises from the rear of the hyoid bone and ends after running through from the upper partof the M. transversus linguae to the apex lingue, while the muscle bundle observable in the lower surface of the lateral side arises from the lower aspect of the M. transversus lin- 
guae at the origin of the hyoid root and runs forward along the lower surface of the bilateral side of the tongue. Especially, a pair of the muscle bundles nearest the M. hyoglossus, as they approach the tip of the tongue, adhere to the lower surface of this muscle and becomes one muscle bundle. However, other muscle bundles end with the apex linguae.

\section{M. verticalis linguae}

The M. verticalis linguae, as seen in Figs. 5 and 6, arises from the medial side of the M. hyoglossus at the origin of the hyoid root before or after the appearance of the M. transversus linguae, or it arises from the bilateral sides. They are, in both cases, a muscle running vertically.

The former runs forward, adhering to the muscle arising from the lower part of the ventral side of the hyoid bone, and runs toward the apex linguae between the M. hyoglossus, ending nearly with the disappearance of the hyoid bone, while the latter intrudes from the back of the tongue into the muscle bundles of the M. longitudinalis linguae below and ends with the apex linguae.

\section{CONCLUSION}

The muscles of the tongue of Eumeces latiscutatus latiscutatus were investigated histologically. The results obtained are as follows:

1. The M. genioglossus arises from the medial side of the tip of the mandibula, running back along the dorsal aspect of the M. geniohyoideus. Following the course from the body of the tongue to its root it intrudes obliquely in to the tongue.

2. The M. geniohyoideus arises from the sulcus mentalis, running backward along the dorsal aspect of the M. inframandibulae, and further, after passing through under the M. hyoglossus, attaches to the lateral side of the hyoid bone.

3. The M. hyoglossus arises from the lateral aspect of the cornu posterius of the hyoid bone and runs forward. After passing by the lateral side of the cartilagines laryngis it penetrates the tongue at the origin of its root, reaching the apex linguae without bifurcating. On the way, a tubulous hyoid muscle which seems to embrace this muscle, appears. This muscle is a retractor and as a muscle penetrating the tongue it is the most favorable in the development.

4. The M. sternohyoideus is regarded as a continuation of the $M$. rectus abdominis. It arises from the ventral side of the sternum passing forward, it reaches the medial side of the hyoid bone.

5. The M. transversus linguae arises from the upper part of the medial side of the M. hyoglossus at the origin of the root of the tongue. Running forward, it gradually spreads out and ends with the apex linguae after passing by along the upper part of this muscle.

6. The M. longitudinalis linguae arises from the back of the tongue or from the lower part of the lateral side at the origin of its root and runs toward the apex linguae above or below the transversal muscle band, respectively. Partially, a pair of the muscle bundle seen on the innermost side under the transversal (on the side of the $M$. hyoglossus) adheres to the lower part of this muscle.

7. The M. verticalis linguae arises from the upper part of the medial side of the M. hyoglossus or from its lateral side at the origin of the tongue root before or after the appearance of 
the M. transversus linguae. The former runs forward between the M. hyoglossus and ends with the disappearance of the hyoid bone, while the latter passes the lateral side and ends with the apex linguae.

The M. genioglossus, the M. geniohyoideus, and the M. hyoglossus in Eumeces latiscutatus latiscutatus are better developed than those in a newt and a little inferior in development to a bull frog, presenting the shape similar to that of a gecko.

However, they are not so much bifurcated as those in a gecko, rather resembling the snakes in respect of the bifurcation.

Therefore, it may be assumed that these findings have something to do with the way how to catch and take in food.

\section{SUMMARY AND DISCUSSION}

Due to the difference in the method of food catch and intake even in the same kind of animals the tongue and the muscles of the tongue are different in shape, respectively. Accordingly, morphological comparisons were performed between the muscles of the tongue of the amphibia (urodela and anura), the reptiles, and the fish and those of Eumeces latiscutatus latiscutatus examined belonging to the reptiles. It was found that in Eumeces latiscutatus latiscutatus, the M. genioglossus and the M. geniohyoideus which pull the tongue forward (the extensor) as well as the M. hyoglossus and the M. sternohyoideus which pull the tongue backward (the retractor) are better developed than those in a newt, urodela of the amphibia, and a little inferior in development to a bull frog (Rana nigromaclata nigromaclata), anura of the amphibia. It was also revealed that, as seen in a newt or in snakes in Formosa reported by Konishi, a tubulous muscle of the tongue was confirmed around the M. hyoglossus, and that the M. hyoglossus was not so much bifurcated from the body of the tongue to its tip, as seen in a newt, rather similar in shape to that of the snakes. Moreover, taking the tongue itself of Eumeces latiscutatus latiscutatus into consideration, though it is difficult for it to catch and take in food by putting out the greater part of the tongue to the outside like a bull frog, it is capable for it to pull out the tongue to some degree as a newt or snakes. In addition, in our case the way to carry food to the esophagus is also functionally conceivable from the shape of the hyoid muscles.

\section{REFERENCES}

Duges, A. (1827). Recherches anatomiques et physiologiques sur la deglutition dans les Reptiles. Ann. d. Sciene. 12, 337-395.

GAuPP, E. (1901). Über Muskelmechanismus bei den Bewegungen der Forschzunge. Anat. Anz. 19, 385-396.

Gegenbaur, C. (1894). Phylogenese der Zunge. Morph. Jahrb. 21, 1-18.

KonISI, K. (1940). Morphologische Untersuchungen der Zunge und der Zungenscheide bei der in Formosa einheimischen Schlangen. Taiwan Med. J. 39, 1408-1940.

Ludwig, F. (1894). Zur Anatomie der Zunge. Eine vergleichend anatomische Studie. Munchen.

Miyazaki, M., Nakamura, T. and Saegusa, H. (1976). On the tongue muscle of Triturus pyrrhoguster, Urodela of the Amphibia. Fukuoka Dent. J. 5, 73-78.

NAKAMURA, T. and MiYAzAKI, M. (1979). On the shape of the M. linguae of Rana nigromaculata. Fukuoka Dent. J. 6, 291-296.

Nakamura, T. and Miyazaki, M. (1979). On the shape of muscles of the tongue of Gecko Japonicus. Fukuoka Dent. J. 6, 363-367.

NAKAMURA, T. and MiYAZAKI, M. (1980). On the shape of muscles of the tongue of Xenopus loevis. Fukuoka Dent. J. 7, 93-98. 


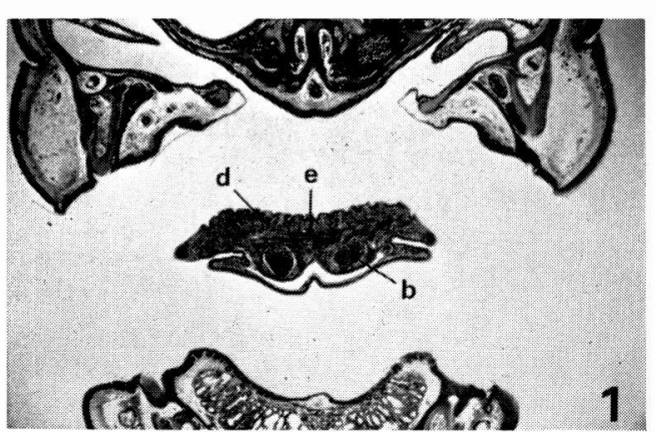

Fig. 1. Light micrograph of the tip of tongue.

b: M. hyoglossus, d: M. longitudinalis linguae, e: M. transversus linguae (frontal section. double-stained with Hematoxylin-Eosin, $\times 20)$.

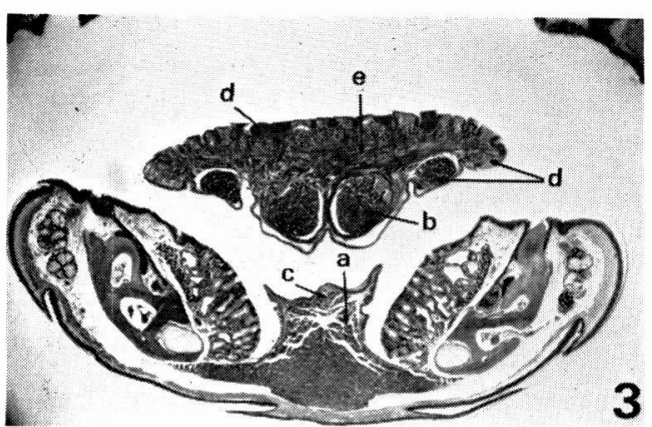

Fig. 3. Light micrograph of the body of tongue, (anterior part)

a: M. geniohyoideus, b: M. hyoglossus, c: M. genioglossus, d: M. longitudinalis linguae, e: M. transversus linguae. (frontal section, double-stained with Hematoxylin-Eosin, $\times 20$ ).

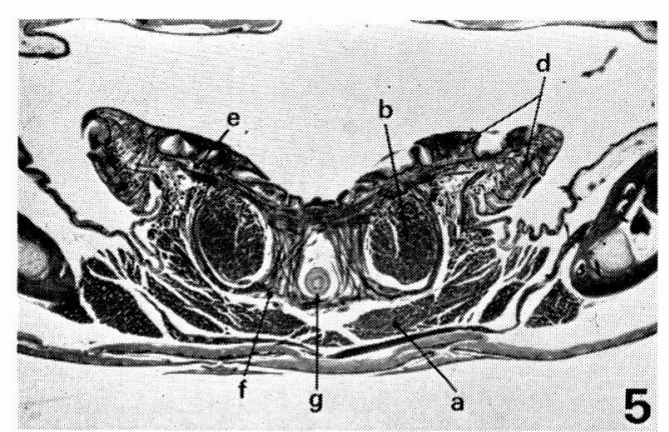

Fig. 5. Light micrograph of the body of tongue (posterior part)

a: M. geniohyoideus, b: M. hyoglossus, d: M. longitudinalis linguae, e: M. transversus linguae, f: M. verticalis linguae, $g$ : Os hyoideum (frontal section, double-stained with Hematoxylin-Eosin. $\times 20$ ).

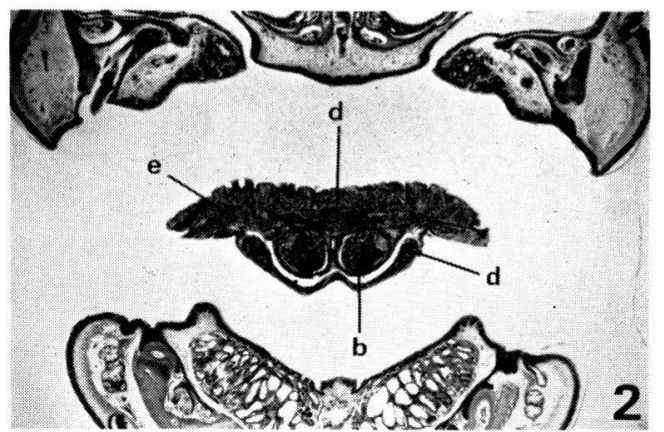

Fig. 2. Light micrograph of the tip of tongue.

b: M. hyoglossus, d: M. longitudinalis linguae, e: M. transversus linguae, (frontal section, double-stained with Hematoxylin-Eo$\sin , \times 20)$.

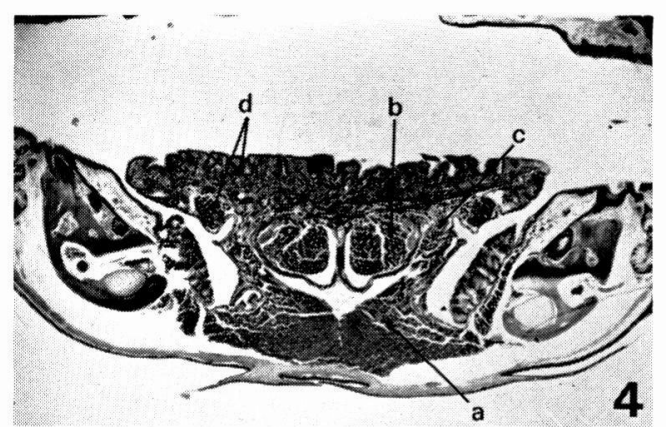

Fig. 4. Light micrograph of the body of tongue (middle part).

a: M. geniohyoideus, b: M. hyoglossus, c: M. genioglossus, d: M. longitudinalis linguae (frontal section, double-stained with Hematoxylin-Eosin, $\times 20)$.

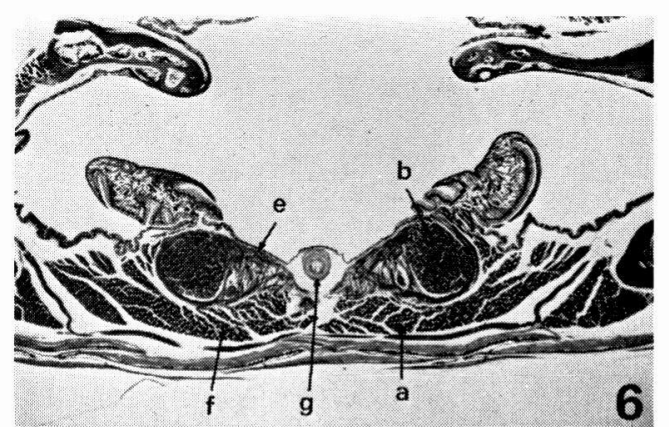

Fig. 6. Light micrograph of the root of tongue

a: M. geniolyoideus, b: M. hyoglossus, e: M. transversus linguae, f: M. verticalis linguae, g: Os hyoideum, (frontal section, double-stained with Hematoxylin-Eosin $\times 20$ ). 